\title{
AYUDAS A LA BANCA EN LA EUROZONA: SOCIALIZAR PÉRDIDAS Y PRIVATIZAR BENEFICIOS
}

\author{
Enrique Casais Padilla \\ Facultad de Ciencias Económicas y Empresariales \\ Universidad Complutense de Madrid
}

\begin{abstract}
La crisis e incertidumbre que padece el sector financiero mundial en 2012 es de tal magnitud que, para muchos expertos, el "tsunami" que pudiera desencadenarse sería mucho más grave que el ocurrido en 2008 con la quiebra de Lehman Brothers. La "barra libre" de liquidez para las principales entidades financieras iniciada por la Reserva Federal de Estados Unidos (FED) ha tenido continuidad por el Banco Central Europeo (BCE) en la Eurozona en 2011 y 2012. No obstante, estas billonarias ayudas concedidas sólo suponen alivios temporales, que en ningún caso van a arreglar los graves problemas de las principales entidades mundiales, mientras se legitiman beneficios especulativos obtenidos durante el periodo de auge que, una vez más, deberán ser soportados por los contribuyentes.
\end{abstract}

El tiempo es un invento para evitar que todo suceda en el mismo instante. Ray CUMmings (1929)

\section{Introducción}

L a crisis económica que empezó en 2007 se encuentra muy lejos de ser solucionada. En 2012, los países centrales se encuentran atrapados en una espiral de recesión, desempleo y deudas. El capitalismo se encuentra confrontado a un problema de realización que aparece desde mediados de la década de 1980, y en la que el papel del sector financiero ha sido crucial, ya que la "solución" al problema de la realización ha consistido en un aumento creciente del endeudamiento que asegure el reciclaje de la plusvalía hacia los ingresos rentistas. Las exigencias desmesuradas de rentabilidad que impone a la economía real refuerzan, a su vez, el débil dinamismo de la inversión y las desigualdades sociales como condición de reproducción del sistema.

Así, vemos que el capitalismo ha sido atrapado por sus contradicciones y se enfrenta hoy a vencimientos a los que no puede hacer frente; la quiebra bancaria es el símbolo de la quiebra capitalista y, hasta la fecha, no se dispone de una solución efectiva de recambio. En estas condiciones, la regulación del sector financiero mundial sería un remedio útil, pero no solucionará las raíces del problema. La financiarización se nutre de la reducción de la parte salarial y de los desequilibrios de la economía mundial, por lo tanto, parar este proceso implica otro reparto de las riquezas y otra organización de la economía mundial; dos perspectivas que hoy en día se encuentran fuera de los planteamientos para solucionar la crisis.

En este contexto de inminente quiebra bancaria mundial, se están buscando desesperadamente soluciones que permita al sistema legitimar y consolidar las plusvalías fraudulentas y ficticias obtenidas en los años de bonanza financiera a base de la creación de complejos productos derivados y de un apalancamiento financiero que queda fuera de cualquier lógica económica o empresarial.

La "solución" para las entidades de la Eurozona ha consistido en una nueva ayuda financiera de más de 1 billón de euros; ayuda que en esencia sólo van a servir para dilatar la catástrofe en el tiempo, ya que si realmente no se realiza ninguna acción complementaria con estos activos en proceso de deterioro, dentro de tres años, cuando haya que devolver la enorme ayuda, el problema será simplemente mucho mayor.

Si el análisis es correcto, entonces, ¿̨por qué se conceden estas ayudas que no solucionan el problema? La hipótesis del presente artículo es que estas ayudas sirven para tapar los agujeros de la contabilidad de los grandes bancos y, de facto, legitiman un billón de euros de beneficios ficticios obtenidos de manera fraudulenta, que una vez más se va a "mover" del dinero de los contribuyentes a los balances privados. Unido a esto, la "barra libre" financiera está sirviendo para que las grandes corporaciones absorban a precios de ganga a los bancos pequeños y cajas de ahorros. Y por si fuera poco, el tiempo "de gracia" concedido va a permitir a los grandes grupos financieros refinanciar sus activos potencialmente problemáticos o en proceso de deterioro, de manera que puedan diseminar y dispersar una buena parte de sus activos por el sistema financiero mundial. Así, el artículo pretende servir como llamada de atención a países como México, respecto a los riesgos potenciales respecto a que la crisis financiera en los países centrales sea "exportada" mediante ventas internas de activos financieros. ${ }^{1}$ 


\section{La financiarización y los canales de distribución de la crisis}

La crisis actual estalló en la esfera financiera pero se ha extendido rápidamente al conjunto de la economía llamada real. La inestabilidad y volatilidad de los mercados financieros, especialmente donde se abandonaron los controles y regulaciones, desembocaron en una crisis de proporciones históricas, con un fuerte y duradero impacto sobre la economía real. La bursatilización que tanto enorgullecía a los partidarios de la globalización neoliberal condujo a la diseminación de los llamados activos tóxicos por todo el sistema financiero.

La crisis financiera se propagó rápida y principalmente a Europa dado que la banca de estos países lleva décadas adoptando las mismas prácticas que la banca de EEUU. Más de cuatro años después del primer estallido de la crisis expresado en la quiebra de Lehman Brothers, parece evidente que la recaída del sector financiero es sólo cuestión de tiempo. En este contexto, muchas miradas cada vez más apuntan a los países periféricos como los siguientes perjudicados, ya que el capital internacional tiene medios suficientes para derivar parte de los costos de la crisis a estas economías.

La crisis actual, por su gravedad y profundidad debería haber cuestionado los fundamentos de los modelos de crecimiento, pero, hasta la fecha, esta revisión no se ha dado.

\section{La gravedad de la crisis financiera y los fallidos rescates bancarios}

Como ha quedado en evidencia en los últimos meses, en los países centrales se ha entrado en un ciclo de total aversión al riesgo y el obligado desapalancamiento que deben realizar las empresas y las instituciones financieras ha secado las líneas de crédito retroalimentando el ciclo descendente de la actividad económica. Este aumento de los riesgos del sistema financiero debido al deterioro de la calidad de los activos puede desencadenar una cascada de quiebras de entidades financieras; lo que se ha denominado "tsunami financiero".

"Las cargas de la deuda privada siguen siendo demasiado altas, el empleo sigue cayendo, y siguen en aumento la morosidad y los desahucios. Los activos están sobrevalorados, aun a los deprimidos precios actuales. Muchas entidades financieras (entre las que probablemente se incluyen las más grandes) son insolventes, sin esperanza, tenedoras de muchedumbres de desechos tóxicos que jamás valdrán nada". ${ }^{2}$ Esta cita de 2009, bien podría estar escrita en 2012, ya que desde entonces, no se ha realizado ningún movimiento serio para solucionar los problemas del sector financiero en los países centrales. Estos problemas de falta de liquidez y de solvencia que amenazan con arrastrar a la banca europea y mundial, son debidos principalmente a: 1) un enorme apalancamiento financiero en activos ficticios,

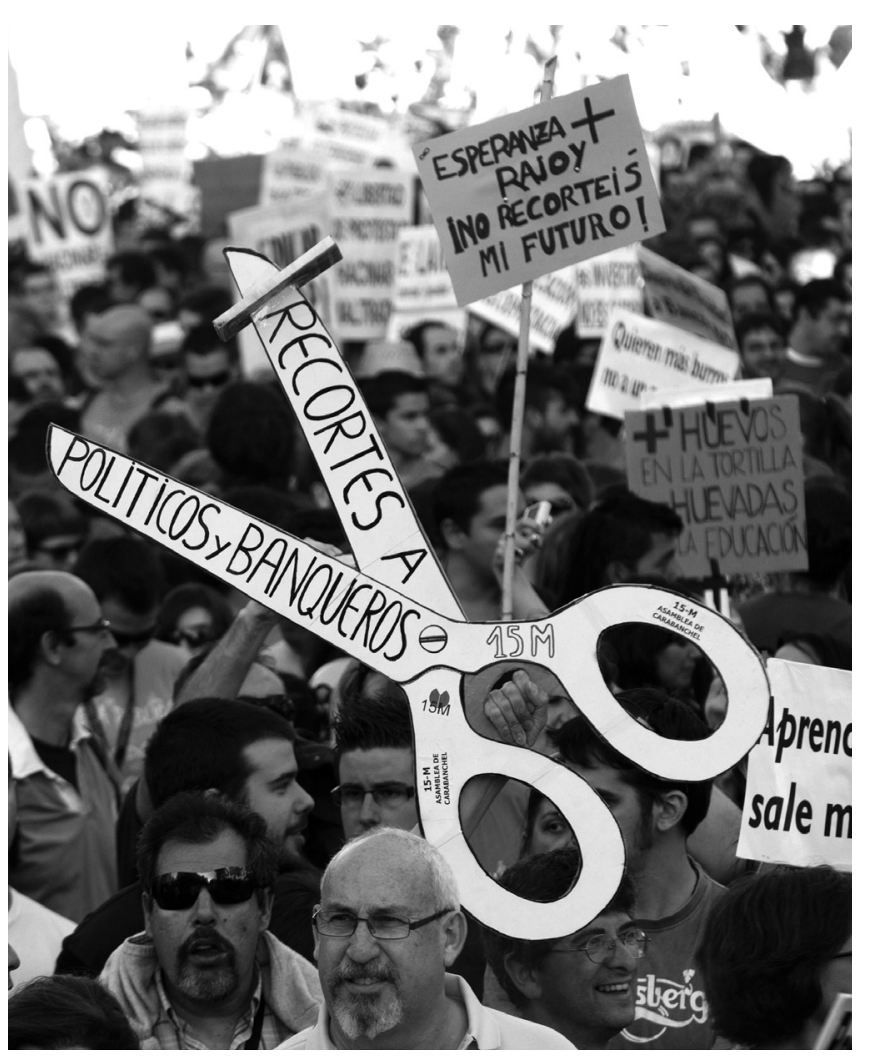

que aún conservan en sus carteras desde el origen de la crisis en $2008 ; 3$ 2) una exposición muy relevante a las deudas soberanas de ciertos países; 3 ) unas cada vez más elevadas tasas de morosidad, consecuencia directa de la crisis y el desempleo; y 4) para el caso concreto de España, Reino Unido y Estados Unidos, una exposición muy relevante al sector inmobiliario.

Las razones de esta barra libre en la Eurozona vienen provocadas por el miedo a un "tsunami financiero" de falta de liquidez. No obstante, esta estrategia dejará a los gobiernos absolutamente maniatados por los bancos para siempre. La gráfica 1 muestra el volumen de activos de los 25 bancos más importantes del mundo respecto al PIB de sus respectivos países al cierre del ejercicio fiscal de 2010. Con las nuevas adquisiciones, fusiones y absorciones, todos estos bancos serán considerados "too big to fall", y el riesgo de una sola quiebra puede provocar una caída en dominó del conjunto del sistema.

El problema de los activos financieros sobrevalorados es la clave para entender cómo se propagó en masa la crisis de las hipotecas subprime, hasta que el mercado secundario se colapsó. Cuando los inversores comenzaron a valorar el riesgo real al valor de mercado de sus activos financieros, se produjo una carrera desenfrenada por rescatar el dinero en efectivo, y como consecuencia, los mercados de dinero al por mayor comenzaron a congelarse, ya que ningún banco se fiaba de los otros para prestar dinero. Así desapareció 


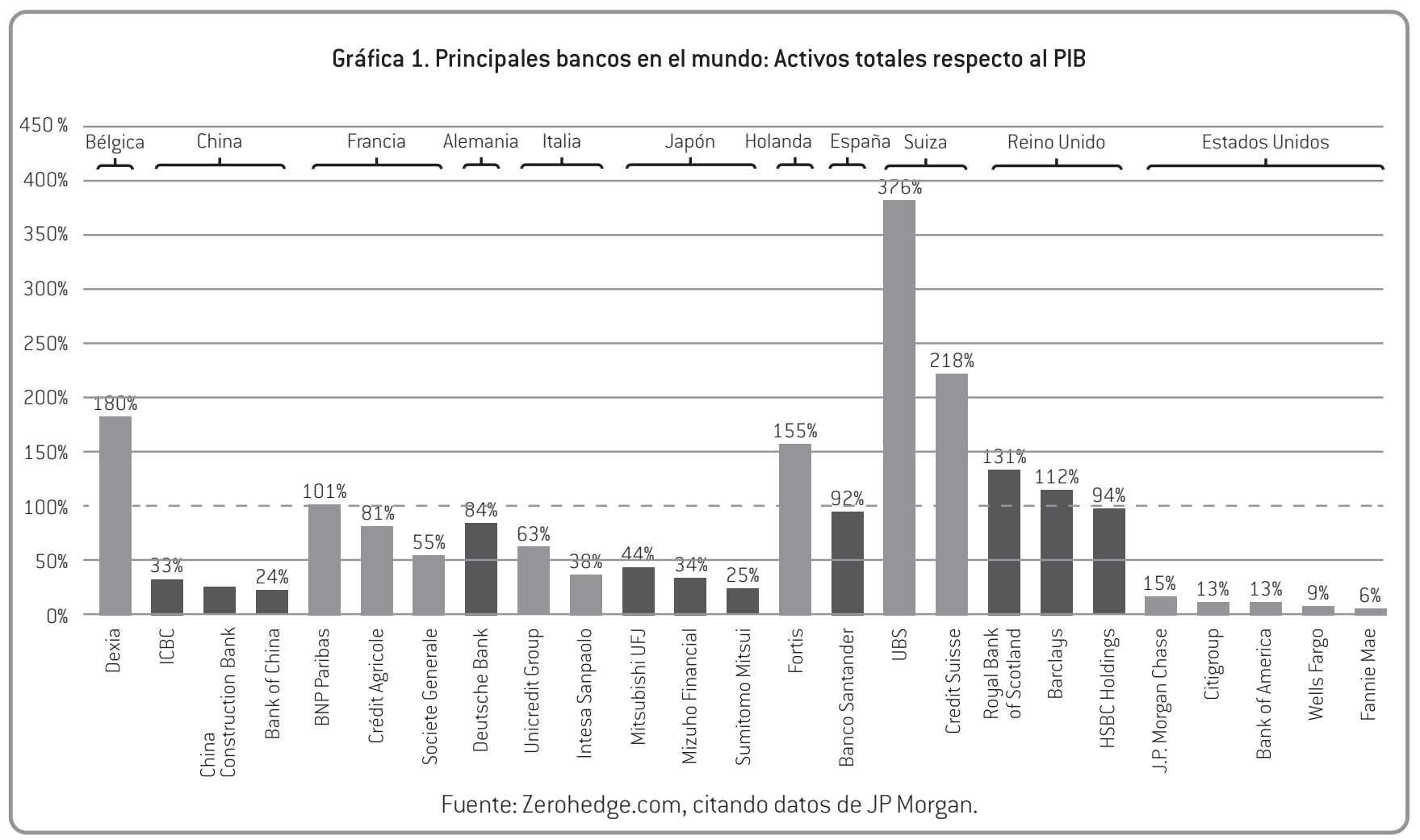

la principal fuente de financiamiento discrecional para los bancos. Este momento, en 2008, fue llamado el "Momento Lehman", es decir, la parálisis de los mercados reflejados en la quiebra del gigante americano.

Durante un par de años pareció que los gobiernos lograron estabilizar los sistemas bancarios en la mayoría de los países mediante el suministro de inyecciones masivas de fondos. ${ }^{4}$ En este contexto, la aparente recuperación de la economía mundial en 2009 produjo también un cierto crecimiento de los depósitos bancarios y una recuperación en el precio de mercado de las acciones bancarias, que incluso permitió que algunos bancos recaudaran nuevo capital. No obstante, la situación a partir de 2010 se ha venido deteriorando rápidamente, principalmente en la Eurozona, con unos problemas de deuda soberana que muestran los graves problemas que sigue arrastrando el sistema financiero de los países centrales.

En otoño de 2011, el costo de los CDS en la Eurozona superó el nivel alcanzado en el momento del colapso de Lehman Brothers en 2008. Y “... el mercado de CDS es el canario en la mina de carbón, el envío de señales de alarma en otro lugar y que puede causar grandes ventas masivas de acciones y bonos". Ante esta situación de desconfianza entre los actores del mercado, que pudiera generar un nuevo "Momento Lehman" que colapsara los mercados financieros mundiales, en diciembre de 2011 el BCE concedió una primera facilidad de liquidez a los bancos de la Eurozona por importe de 500 mil millones de euros y a finales de febrero de 2012, otros $500 \mathrm{mil}$ adicionales. ${ }^{6}$ Esta inyección de dinero a la banca permite alejar los fantasmas del corralito que empezaban a cernirse sobre la Zona Euro. Se trata de una postergación del problema en el tiempo que pretende ayudar a que los bancos "estructuren" sus balances y puedan sanear sus activos en los tres años siguientes, mientras que a corto plazo, se les sigue ayudando de una manera escandalosa con el negocio del "carry trade".

Lo que no ha explicado el BCE, ni ninguna autoridad monetaria, es cómo se van a "sanear" los activos de los bancos, ya que la profunda crisis a la que se enfrentan los países centrales van a seguir deteriorando los activos de las entidades financieras; no sólo los ya "tóxicos", sino los que hoy gozan de buena salud y en su momento fueron concedidos utilizando las prácticas de gestión de riesgos razonables.

Quienes en el mundo toman decisiones políticas siguen alimentando la ficción de que se trata sólo de un problema de falta de liquidez temporal, y no, como es la verdad, de un problema de excesivo apalancamiento, de excesivo endeudamiento y de unos activos heredados increíblemente sobrevalorados, basados en unos escenarios económicos de permanente burbuja especulativa.

Además, la "barra libre" financiera tendrá consecuencias a medio plazo en la Eurozona. El balance del $\mathrm{BCE}$ va a quedar seriamente deteriorado, ya que se ha 


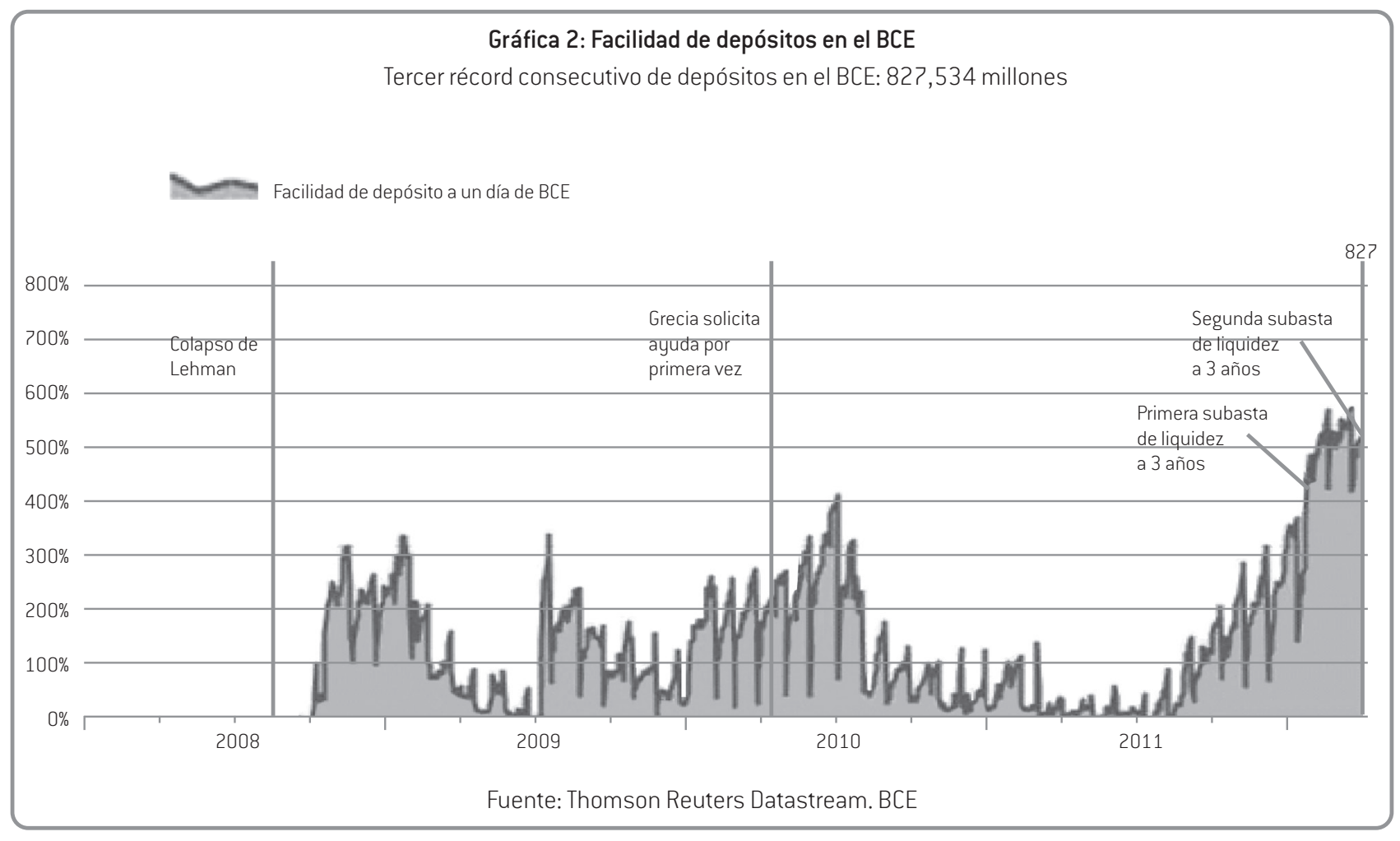

aceptado todo tipo de activos como garantía a cambio del dinero. Las inyecciones de liquidez no sólo son injustas, sino que además son absolutamente ineficientes para los objetivos declarados por parte del BCE. Tras la subasta a tres años del BCE, el 29 de febrero, la banca guardó en la "caja fuerte" del BCE 827534 millones de euros, más del $80 \%$ de todo el dinero que acababa de ser prestado por parte del BCE con el objetivo declarado de "impulsar la confianza" entre las entidades y volver a "reanudar la senda de crédito" hacía la economía real. La escasa predisposición de los bancos a prestarse entre ellos, al optar por la mayor seguridad del BCE, en vez de buscar mayores rendimientos, impide a su vez que este dinero fluya a la economía real, ya que el dinero vuelve al organismo monetario. ${ }^{8}$

La gráfica 2 muestra la evolución de la liquidez depositada por las entidades financieras en el BCE. La actual desconfianza entre los bancos de la Eurozona es de tal magnitud que supera ampliamente a los momentos previos al colapso del sistema en 2008.

la historia de deslegitimación del sistema capitalista neoliberal, puesto que se facilita la supervivencia a un tipo de agentes económicos mientras que no a otros. La economía real -que genera valor- está sujeta a las implacables reglas del mercado, mientras que al sector financiero, cuya misión debiera consistir en realizar una asignación efectiva de recursos, se le permite "escapar" a la rigidez del sistema.

\section{Conclusiones}

A la vista de lo expuesto, y a pesar de la opacidad con la que se gobiernan las entidades financieras, parece claro que la situación actual de las principales entidades financieras de los países centrales, es cuando menos muy preocupante, con unas necesidades muy acuciantes de desapalancamiento financiero, y para los casos concretos de España, Estados Unidos y Reino Unido, una cada vez mayor preocupación por sus activos hipotecarios, que corren el riesgo de convertirse en importantes fallidos si prosigue el deterioro económico a ambos lados del Atlántico.

En este complicado escenario, la "barra libre" financiera otorgada por el BCE entre diciembre de 2011 y febrero de 2012, ha supuesto un enorme alivio y va a permitir un tiempo extra a estas entidades para "sanear" sus cuentas y ajustar sus balances. Además, esta acción, al igual que ocurrió en Estados Unidos con las ayudas de la FED, abre la puerta a las refinanciaciones de créditos que alejan en el tiempo futuros problemas de riesgos. Con estas operaciones se permitirá disponer de cuando menos tres años de holgura a créditos problemáticos, clasificados normales, que con la refinanciación se impide que caigan en morosidad. Asimismo, los bancos "demasiado grandes para caer" son hoy mayores que nunca como resultado de las fusiones inducidas por la crisis y las ayudas.

A pesar de las excepcionales medidas adoptadas, el comportamiento de los mercados bancarios sigue mostrando 
una absoluta aversión al riesgo y la desconfianza dentro del sistema es total. Las cifras depositadas como refugio diariamente en el BCE superan ampliamente a los momentos previos a la quiebra de Lehman Brothers, lo que impide que se cumplan los objetivos declarados por el BCE a la hora de conceder estas ayudas: que fluya el dinero hacia la economía real restaurando el crédito en el sistema.

Se ha creado el mito de que sin el sistema financiero nada puede funcionar. Si CitiGroup, JP Morgan o Deutsche Bank desaparecieran todo seguiría exactamente igual. Es cierto que un cese total de la banca generaría ondas de choque en términos de aumento en las tasas de interés y caída en el valor de las acciones. Pero este shock transitorio no duraría más de uno o dos años. Seguir apuntalando y legitimando los fraudes financieros cometidos no tiene ningún sentido ni económico ni, por supuesto, moral.

Ninguna de las causas que nos llevaron a la crisis ha sido seriamente cuestionada, ni parece que, salvo que ocurra el temido "tsunami financiero" se vaya a plantear en el mundo capitalista ninguna reforma que permita a la mayoría de la población mundial asegurarse un futuro digno. Resulta perturbador que el sector financiero y sus apoyos del mundo de la política puedan devastar la economía mundial y arruinar millones de vidas, y seguir manteniendo el control de la política sin pagar las justas responsabilidades por sus actos.

\section{Referencias}

${ }^{1}$ El proceso de financiarización, los canales de distribución de la crisis y cómo se pueden derivar estos activos potencialmente dudosos de los países centrales hacia las economías emergentes se encuentra desarrollado en Casais, Enrique (2012), "Crisis financiera en Europa y Estados Unidos, ¿Problemas para México?”, en 30 Aniversario del Colegio de la Frontera Norte (en prensa).

${ }^{2}$ The Washington Note, "Financial Crisis is Not a Clogged Sewer Problem”, entrevista a James Galbraith, 2009 http:// www.thewashingtonnote.com/archives/2009/02/americas_financ/.

${ }^{3}$ Los niveles de apalancamiento de la banca europea en los años previos a la crisis se instalaron en niveles de $20 \mathrm{y}$ 30. Esto indica que por cada euro, la banca creó 20 euros desde la nada. Ningún otro sector de la economía goza de tal privilegio, ya que la creación de nuevo valor es producto de un complejo proceso de transformación de insumos en productos, y muy rara vez el resultado final de los factores productivos llega a ser 20 o 30 veces su costo. Respecto a la banca estadounidense, bancos como CitiGroup o Goldman Sachs llegaron a niveles de apalancamiento del $100 \%$ y más, lo que indica que con cada dólar creaban 100 dólares de la nada. El problema que encierra este fenómeno, es que basta una caída del 1\% en el valor de las acciones para que se pierda todo el capital real, y quede sólo el dinero ficticio. Por eso, el proceso de billonarias ayudas por parte de los bancos centrales busca rellenar esos enormes agujeros creados en el período del auge. Pero estas ayudas infligen un severo castigo a todos los contribuyentes que quedaremos atrapados durante generaciones por la legitimación de estas deudas, fruto del fraude financiero. Una vez más, se trata de socializar las pérdidas y privatizar beneficios.

${ }^{4} \mathrm{Al}$ inicio de la crisis, en 2007 , los activos tóxicos en manos de los bancos europeos, mayoritariamente alemanes y franceses sumaban ocho billones de dólares. Entonces, la Comisión Europea permitió a los bancos que trasladaran los activos tóxicos a las carteras de vencimiento del balance. No tuvieron que provisionar nada por las posibles pérdidas y allí quedaron, ocultos a la luz pública. Y allí siguen. Sólo los supervisores de cada país conocen la cifra exacta de estos "activos". El objetivo del regulador al permitir la ocultación de esta bomba de relojería era evitar que la banca pusiera los activos a precio de mercado, que era casi cero, y terminara por quebrar, como le ocurrió a Lehman Brothers. ("La UE recorta el valor de la deuda, pero admite al 100\% los activos tóxicos", El País, 23/10/2011) A pesar de todo esto, el BCE admite estos activos para trasladarlos a fondos de titulización con los que han obtenido financiación de cerca del $50 \%$ adicional. De ahí que pese a la enorme inyección de capital público, la valoración de algunas entidades financieras está por debajo no sólo de lo reflejado por su valor en libros contables, sino de los importes que han recibido por parte de las autoridades, una muestra clara de la desconfianza respecto a los activos contabilizados.

${ }^{5}$ Financial Times (2011: 21).

${ }^{6} \mathrm{El} 29$ de febrero de 2012, el BCE adjudicó algo más de medio billón de euros en dinero fácil a tres años y a un tipo de interés del $1 \%$. Se trata de la segunda subasta, tras la realizada en diciembre, en la que 523 entidades pidieron $489 \mathrm{mil}$ millones. Esta vez fueron 800 bancos y 530 mil millones. La "barra libre" ha supuesto un diluvio de liquidez de más de un billón de euros a tres años para el maltrecho sistema financiero del continente.

${ }^{7}$ El carry trade es una ventajosa práctica para la banca, que consiste en financiarse al $1 \%$, y vender directamente esa financiación al Estado al 3-5\%, obteniendo varios puntos porcentuales de ganancia por cada unidad monetaria desplazada.

${ }^{8} \mathrm{La}$ facilidad de depósito del BCE remunera el dinero depositado diariamente por los bancos de la Eurozona al 0.25\%, una rentabilidad muy inferior al $1 \%$ del precio oficial del dinero, y muchísimo menor de los rendimientos del mercado interbancario a un día, que se encuentran en torno al $3 \%$. 